\title{
EMSF
}

EDUCAÇÃO MATEMÁTICA SEM FRONTEIRAS

\section{CONHECIMENTOS DIDÁTICO-MATEMÁTICOS PARA O ENSINO DOS NÚMEROS RACIONAIS}

\section{DIDATIC-MATHEMATICAL KNOWLEDGE FOR THE TEACHING OF RATIONAL NUMBERS}

\author{
Patrícia Pujól Goulart Carpes ${ }^{1}$ \\ Eleni Bisognin ${ }^{2}$
}

\begin{abstract}
Resumo
O presente trabalho apresenta resultados de uma pesquisa que visa identificar e discutir os conhecimentos didático-matemáticos sobre números racionais mobilizados por alunos em formação inicial, ao resolverem atividades sobre esse conteúdo. Foram propostas questões aos participantes, durante o desenvolvimento de uma oficina, a fim de mobilizar conhecimentos do professor para ensinar números racionais. Os dados foram obtidos a partir dos registros escritos dos participantes, feitos durante o desenvolvimento das atividades propostas. Para análise dos dados foi utilizado o modelo de Conhecimentos DidáticoMatemáticos, definido por Godino, considerando-se a Dimensão Didática com ênfase na faceta epistêmica. Com esse modelo é possível a identificação dos conhecimentos do professor tais como: os encaminhamentos das lições, as estratégias de solução, o conhecimento matemático empregado, trocas de registros e significados do número racional. Os resultados apontam que os alunos, em sua grande maioria, apresentaram dificuldades para reconhecerem as diferentes representações de um número racional e para propor soluções por meio do uso de distintos procedimentos apresentados durante a oficina. Como ponto positivo destaca-se a oportunidade propiciada aos alunos para (re)conhecerem e refletirem sobre os conhecimentos necessários ao professor para ensinar esse tópico.
\end{abstract}

Palavras-Chave: Número racional; Dimensão epistêmica; Formação inicial do professor; Conhecimento matemático para o ensino.

\begin{abstract}
This work presents results of a research that aims to identify and discuss didactic-mathematical knowledge about rational numbers mobilized by students in initial formation when solving activities on this content. Questions were offered to participants during the development of a workshop to mobilize teacher knowledge to teach rational numbers. The data were obtained from the written records of the participants made during the development of the proposed activities. For the analysis of the data was used the DidacticMathematical Knowledge model, defined by Godino, considering Didactic Dimension with emphasis on the epistemic facet. With this model, it is possible to identify the teacher's knowledge such as: lesson referrals, solution strategies, mathematical knowledge, change of registers and rational number meanings. The results show that the majority of the students presented difficulties to recognize the different representations of a rational number and to propose solutions through the use of different procedures presented during the workshop. As a positive point stands out the opportunity given to the students to (re) know and reflect on the knowledge needed for the teacher to teach this topic.
\end{abstract}

Keywords: Rational Number; Epistemic dimension; Initial teacher training in mathematics; Mathematical knowledge for teaching.

\footnotetext{
${ }^{1}$ Doutoranda em Ensino de Matemática: Universidade Franciscana, Área Tecnológica, patigou23.carpes@gmail.com

${ }^{2}$ Doutora em Matemática: Universidade Franciscana. Área Tecnológica, eleni@unifra.br
} 
Educação Matemática Sem Fronteiras, Chapecó, v. 1, n.1, p. 23 - 39, jan-junho,2019.

\section{Introdução}

O presente trabalho tem como propósito apresentar resultados parciais de uma investigação que visa identificar e analisar os conhecimentos didático-matemáticos sobre números racionais mobilizados por licenciandos em Matemática, durante uma formação realizada tendo por base a perspectiva do modelo denominado Conhecimentos DidáticoMatemáticos, (CDM), relacionado ao Enfoque Ontossemiótico de Conhecimento e Instrução Matemática (EOS), conforme Godino, Batanero, Font (2007) e Godino (2009) e colaboradores.

O tema motivador para este estudo são os números racionais, que de acordo com (Ripoll, Ripoll, Silveira, 2009) são definidos como números da "forma $r=$

$\frac{a}{b}$ onde $a, b \in Z$ e $b \neq 0$ em que $r$ é a classe de todas as frações equivalentes a $\frac{a}{b}$, .Esta definição é normalmente a única forma de representação proposta aos alunos do Ensino Fundamental, etapa considerada neste estudo.

De acordo com o modelo EOS, a idoneidade didática é um critério sistêmico de adequação e pertinência a respeito da proposta educativa. Constitui-se de seis facetas que interagem de forma coerente entre si, sendo elas: a epistêmica (se refere ao grau de representatividade dos significados institucionais implementados), a cognitiva (expressa o grau em que os significados pretendidos/implementados são presentes na base de entendimento dos alunos), a interacional (as configurações e trajetórias didáticas permitem identificar conflitos semióticos potenciais e permitem resolver os conflitos que se produzem durante o processo de instrução), a mediacional (disponibilidade e adequação dos recursos materiais e temporais necessários para o desenvolvimento do processo de ensino aprendizagem), a afetiva (interesse do aluno, fatores que dependem basicamente do aluno e de sua história escolar previa), a ecológica (processo de estudo se ajusta ao projeto educativo da escola e da sociedade), (Godino, Batanero, Font, 2007).

Diferentes dimensões tornam um processo de ensino e aprendizagem idôneo. $\mathrm{O}$ professor deve ter em mente que um processo idôneo requer conhecimentos específicos, tais como o conhecimento de referência, o planejado e o possível de ser alcançado no nível de estudo do aluno, por exemplo. Ou, ainda, os recursos e métodos que potencializam a aprendizagem do aluno. 
Educação Matemática Sem Fronteiras, Chapecó, v. 1, n.1, p. 23 - 39, jan-junho,2019.

Assim, neste trabalho, são analisados os conhecimentos do professor para ensinar os números racionais considerando-se os aspectos do modelo de Conhecimentos Didático-Matemáticos, de acordo com Godino (2009) e colaboradores.

\section{Números racionais}

O conjunto dos números racionais, especificamente no Ensino Fundamental, anos finais, tem se revelado uma problemática tanto para o ensino quanto para a aprendizagem. A superação de concepções errôneas por parte dos alunos, tais como se $2<3$, então $\frac{1}{2}<\frac{1}{3}$ ou 1,2<1,123 no entendimento que 1,2 tem duas casas decimais e 1,123 têm quatro casas decimais, tem tornado o trabalho do professor cada vez mais complexo.

Diante destas dificuldades, muitas vezes, oriundas da passagem do campo dos números inteiros para os racionais, os alunos tendem a empregar as mesmas propriedades de um conjunto no outro, porém isso nem sempre é válido. Neste sentido, cada vez mais torna-se necessário um bom planejamento do material de ensino do professor para que a compreensão de número racional - em qualquer registro - seja alcançada pelo aluno no Ensino Fundamental.

Romanatto (1997) destaca que as dificuldades de aprendizagem podem, também, ser advindas da própria complexidade do conjunto dos números racionais. O autor aponta para a teia de relações nele incidentes ou emergentes para a efetiva compreensão do número racional. $\mathrm{O}$ autor discorre que é importante o trabalho do professor com essa teia de relações para a efetiva compreensão do objeto matemático, pois, quando o conceito é empregado num contexto particular, pode implicar na validade de algumas relações e propriedades mas não necessariamente de todas.

Diante dos distintos contextos que o número racional representa, Kieren (1975), do ponto de vista pedagógico, observou que esse conjunto numérico é constituído de diferentes construtos e que sua compreensão mais ampla depende do entendimento destes diferentes significados. Na sequência, Kieren (1980), indicou cinco ideias básicas para a compreensão dos números racionais, sendo elas: a parte/todo, o quociente, o operador, a medida e a razão.

Kieren (1980), aponta ainda que, a compreensão completa dos números racionais requer não só a compreensão de cada um dos significados separados, mas como eles se 
Educação Matemática Sem Fronteiras, Chapecó, v. 1, n.1, p. 23 - 39, jan-junho,2019. relacionam. No quadro 1, são apresentadas a definição e uma exemplificação dos cinco significados propostos.

Quadro 1 - Definição e exemplificação dos significados dos números racionais

\begin{tabular}{|c|c|}
\hline Definição & Exemplificação \\
\hline $\begin{array}{l}\text { Parte/todo: apresentado sob a forma } \frac{1}{n} \text { em que } \\
\text { esta fração representa uma das n partes iguais } \\
\text { que a unidade foi dividida. }\end{array}$ & $\begin{array}{l}\text { A fração } \frac{1}{3} \text { representa as bolinhas que estão } \\
\text { pintadas, pois o total de bolinhas foi dividido } \\
\text { em } 3 \text { partes iguais e } 1 \text { foi considerada. }\end{array}$ \\
\hline $\begin{array}{l}\text { Quociente: remete à ideia de partilha, em que } \\
\text { a fração } \frac{a}{b} \text { indica o quociente } a: b, b \neq 0 \text {. } \\
\text { Neste significado, o entendimento de } \\
\text { dividendo e divisor da operação de divisão } \\
\text { deve estar claro, pois dividir em partes iguais } \\
\text { é a base para que se compreendam os } \\
\text { racionais como quocientes. }\end{array}$ & $\begin{array}{l}\text { A fração } \frac{1}{3} \text { representa a quantidade que cada } \\
\text { pessoa receberá se for dividido } 1 \text { bolo } \\
\text { igualmente entre } 3 \text { pessoas. }\end{array}$ \\
\hline $\begin{array}{l}\text { Operador: está associado à ideia de modificar } \\
\text { uma grandeza contínua, tanto aumentar } \\
\text { quanto diminuir, considerando a fração } \\
\text { imprópria ou própria, respectivamente. }\end{array}$ & $\begin{array}{l}\text { Dos } 90 \text { deputados presentes, é necessário } \frac{1}{3} \\
\text { dos votos para aprovação da emenda. Deste } \\
\text { modo, são necessários } 90 \cdot \frac{1}{3}=\frac{90}{3}=30 \text { votos. }\end{array}$ \\
\hline $\begin{array}{l}\text { Medida: identifica a unidade de medida. } \\
\text { Determinar um comprimento e medir um } \\
\text { comprimento através da repetição da unidade } \\
\text { de medida - iteração. }\end{array}$ & $\begin{array}{l}\text { Identifique na reta numérica quantos } \frac{1}{3} \text { cabem } \\
\text { entre } \frac{15}{9} \text {. }\end{array}$ \\
\hline $\begin{array}{l}\text { Razão: surge da relação de duas quantidades, } \\
\text { sendo necessário o raciocínio multiplicativo. } \\
\text { Deve-se fazer uma distinção entre a noção de } \\
\text { razão parte/parte (duas partes de um todo ) e a } \\
\text { razão de grandezas de tipos diferentes, dando } \\
\text { origem a uma nova grandeza. }\end{array}$ & $\begin{array}{l}\text { A cada } 90 \text { candidatos, } 30 \text { são aprovados. } \\
\text { Equivalente a cada } 3 \text { candidatos, } 1 \text { é aprovado. } \\
\text { Isto é, } \\
\qquad \frac{30}{90}=\frac{1}{3} .\end{array}$ \\
\hline
\end{tabular}

Fonte: adaptado de Lamon (2006).

Além da compreensão dos significados dos racionais, é necessário o estudo das suas representações, visto que os números racionais não são apenas as frações ou os decimais e, ainda, a interpretação de uma situação pode ser mais simples a um indivíduo utilizando-se uma representação do que outra. A figura 1 ilustra algumas possibilidades de registros do número racional um meio.

Figura 1 - representações do número racional um meio.

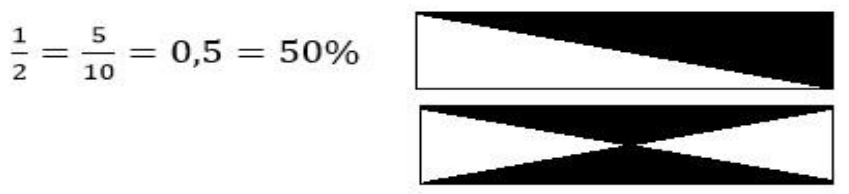

Fonte: da pesquisa. 
Educação Matemática Sem Fronteiras, Chapecó, v. 1, n.1, p. 23 - 39, jan-junho,2019.

Segundo Duval (2003), o que difere a matemática de outras áreas do conhecimento é sua abstração desencadeada por processos de generalizações. O conhecimento matemático necessita de uma representação para se desenvolver e/ou compreender.

Assim, percebe-se que é necessário, para a plena compreensão do número racional, que o aluno consiga transitar entre os diferentes registros de representação semiótica, como também, transite entre os significados dos números racionais.

\section{Os conhecimentos didático-matemáticos}

Nos últimos anos, as investigações na formação inicial ou continuada de professores têm avançado e apontado para os conhecimentos necessários aos professores de Matemática, em específico, para propiciar a aprendizagem de seus alunos (Shulman, 1986, 1987; Ball, Thames e Phelps, 2008; Schoenfeld e Kilpatrick, 2008 e Godino, 2009).

Em se tratando de uma teia de conhecimentos, por muitas vezes complexos, a identificação dos mesmos e a forma de alcançá-los têm criado uma série de estudos e apontam para os conhecimentos do conteúdo específico (matemáticos), como também, os conhecimentos para o seu ensino como necessários ao professor.

Diante da complexidade, das interações envolvidas, na determinação/exploração e, assim, na possibilidade de potencializar esses conhecimentos necessários ao professor para um ensino idôneo, optou-se pelo modelo denominado Conhecimentos DidáticoMatemáticos (CDM), desenvolvido por Godino (2009) e colaboradores. O modelo intenta determinar pautas e critérios que permitem analisar e caracterizar o conhecimento didático-matemático necessário aos professores para o ensino de temas específicos de matemática, (Pino-Fan, Font e Godino, 2014).

Para tal, o modelo CDM constitui-se de três categorias/dimensões: a matemática, a didática e a meta didático-matemática. As categorias elaboradas estão relacionadas com os tipos de ferramentas teóricas de análise do EOS, e cada ferramenta põe em jogo conhecimentos didático-matemáticos.

A dimensão Matemática é composta por duas subdimensões: do conhecimento comum e do conhecimento ampliado, que atende a necessidade de solidificar os conhecimentos dos professores em tópicos específicos de Matemática. Os autores entendem como conhecimento comum aquele conhecimento matemático compartilhado 
Educação Matemática Sem Fronteiras, Chapecó, v. 1, n.1, p. 23 - 39, jan-junho,2019. pelo professor e pelo aluno, isto é, o conhecimento suficiente para resolver um problema por exemplo. O conhecimento ampliado é aquele que o professor deve ter sobre as noções matemáticas, saber vincular o objeto de estudo com outras noções matemáticas e encaminhar os alunos a estudos subsequentes, (Pino-Fan; Godino, 2015).

O professor na sua prática de ensino deve ter conhecimento de diversos fatores que interferem no planejamento e desenvolvimento de um conteúdo matemático. Neste contexto, é proposta a dimensão didática do CDM. A mesma é composta de seis facetas, a saber: faceta epistêmica (conhecimento especializado de Matemática), faceta cognitiva (conhecimento de aspectos cognitivos dos alunos), faceta afetiva (conhecimento dos aspectos afetivos, emocionais e atitudes dos estudantes), faceta interacional (conhecimento sobre interações presentes na sala de aula), faceta mediacional (conhecimento dos recursos e meios que potencializam a aprendizagem dos alunos) e a faceta ecológica (conhecimento sobre aspectos curriculares, sociais, políticos que influenciam na gestão da aprendizagem dos alunos).

A articulação de concepções envolvidas na faceta epistêmica compreende os conhecimentos da matemática escolar com maior profundidade e amplitude (Schoenfeld; Kilpatrick, 2008) como, também, o conhecimento especializado do conteúdo (Ball; Thames; Phelps, 2008). Deste modo, esta faceta leva em conta a ferramenta configuração ontossemiótica do EOS e indica que,

O professor deve ser capaz de mobilizar diversas representações de um objeto matemático, resolver a tarefa mediante distintos procedimentos, vincular o objeto matemático com outros objetos matemáticos de nível educativo no que se ensina ou de níveis anteriores ou posteriores, compreender e mobilizar a diversidade de significados parciais para um mesmo objeto matemático (que integram o significado holístico para este objeto), proporcionar diversas justificativas e argumentos, e identificar os conhecimentos postos em jogo durante a resolução de uma tarefa matemática. (Pino-Fan; Godino, 2015, p. 99)

Pino-Fan e Godino (2015), propõem as seis facetas da dimensão didática para poder analisar, descrever e desenvolver o conhecimento dos professores em diversas fases do processo de ensino e aprendizagem de tópicos de Matemática. Além disso, os professores podem, como parte de seus conhecimentos didático-matemáticos, conhecer e compreender os aspectos envolvidos em cada uma das fases da trajetória didática que compreende um estudo preliminar, planejamento, implementação e avaliação. 
Educação Matemática Sem Fronteiras, Chapecó, v. 1, n.1, p. 23 - 39, jan-junho,2019.

A dimensão meta didático-matemático é composta por duas subdimensões: uma relativa aos conhecimentos sobre os critérios de idoneidade didática e a outra, os conhecimentos sobre as normas e as condições e restrições do ambiente. A idoneidade didática tem o caráter de avaliar o processo de ensino e aprendizagem, isto é, nela está presente a reflexão, a avaliação e a detecção das melhores potencialidades da prática. Segundo Schoenfeld e Kilpatrick (2008), a reflexão habitual da sua própria prática de ensino pode ser o principal mecanismo para melhorar a própria prática. Neste sentido, via o EOS, o CDM prevê critérios de idoneidade que permitem ao professor realizar uma reflexão da sua prática.

Em se tratando de mobilizar conhecimentos por meio de uma formação continuada de professores de matemática, Godino et al (2013), elaboraram um guia tomando componentes e indicadores para a idoneidade de programas de formação de professores para a análise dos dados. Nele incluíram princípios didático-matemáticos relativos às seis dimensões/facetas (epistêmica, cognitiva, afetiva, mediacional, interacional e ecológica) implicadas em um processo de instrução matemática. O quadro 2 apresenta os componentes do Guia de Avaliação da Idoneidade Didática de Processos de Instrução em Educação Matemática, GVID-IDM.

Para tal, o guia propõe indicadores para que sejam considerados para o planejamento, implementação e avaliação de uma formação e, deste modo, se alcance a idoneidade didática do processo vivenciado.

Tomou-se especificamente a faceta epistêmica deste guia como a principal ferramenta para a análise e avaliação da formação inicial desenvolvida neste estudo e, por entendermos que nesta dimensão estão incluídos os conhecimentos especializados do professor, que é objetivo proposto, a mobilização dos conhecimentos didáticomatemáticos quanto ao objeto matemático número racional.

A idoneidade epistêmica é alcançada quando o professor conhece, compreende e domina o conhecimento especializado do conteúdo, utiliza uma variedade de situações problemas, linguagens, estruturas, argumentações e conexões, para o nível educativo em que o professor exerce seu trabalho e faz articulação com o nível educativo posterior (Godino et al, 2013). 
Quadro 2: Componentes do GVID-IDM

\begin{tabular}{|c|c|}
\hline \multirow{6}{*}{ Faceta epistêmica } & $\begin{array}{l}\text { Conteúdo matemático: problemas, linguagem, conceitos, } \\
\text { procedimentos, proposições, argumentos, conexões. }\end{array}$ \\
\hline & $\begin{array}{l}\text { Conteúdo cognitivo: conhecimentos prévios, adaptações } \\
\text { curriculares, aprendizagem do conteúdo matemático por parte } \\
\text { dos alunos. }\end{array}$ \\
\hline & $\begin{array}{l}\text { Conteúdo afetivo: interesses, atitudes, emoções } \\
\text { aprendizagem do conteúdo matemático dos alunos. }\end{array}$ \\
\hline & $\begin{array}{l}\text { Conteúdo interacional: modos de interação e o discurso no } \\
\text { processo de ensino e aprendizagem da matemática. }\end{array}$ \\
\hline & $\begin{array}{l}\text { Conteúdo ecológico: currículo, inovação, didática, adaptação } \\
\text { sócio-profissional, conexões interdisciplinares. }\end{array}$ \\
\hline & $\begin{array}{l}\text { Conteúdo mediacional: uso de recursos tecnológicos no } \\
\text { processo de ensino e aprendizagem de matemática. }\end{array}$ \\
\hline Faceta cognitiva & $\begin{array}{l}\text { Aprendizagem do conteúdo didático-matemático pelos } \\
\text { professores. }\end{array}$ \\
\hline Faceta afetiva & $\begin{array}{l}\text { Crenças, atitudes, interesses, emoções dos professores para a } \\
\text { aprendizagem do conteúdo didático-matemático. }\end{array}$ \\
\hline Faceta interacional & $\begin{array}{l}\text { Modos de interação e discurso no processo de formação de } \\
\text { professores. }\end{array}$ \\
\hline Faceta mediacional & $\begin{array}{l}\text { Uso de recursos tecnológicos no processo de formação de } \\
\text { professores. }\end{array}$ \\
\hline Faceta ecológica & $\begin{array}{l}\text { Currículo, inovação, didática em formação de professores, } \\
\text { conexões interdisciplinares. }\end{array}$ \\
\hline
\end{tabular}
Fonte: adaptado de Godino et al (2013, p.9)

A idoneidade ecológica se conseguirá mediante a leitura e discussão de fontes documentais e estudo de casos de boas práticas que contemplem a inovação, interdisciplinaridade, o desenvolvimento do pensamento crítico e de valores democráticos através do estudo da Matemática. A idoneidade cognitiva deve contemplar a psicologia da aprendizagem matemática, os princípios gerais da aprendizagem de cada conteúdo, compreender e justificar fatos/passos da aprendizagem e apoiar marcos teóricos, desenvolver instrumentos de avaliação pertinentes. A idoneidade afetiva para ser considerada alta, requer do professor conhecimento e compreensão do interesse, necessidades, atitudes e emoções na aprendizagem da Matemática, assim como competência para criar entornos de aprendizagem que sejam de interesse para o estudante.

A idoneidade interacional será alta quando o professor desenvolver competência para a comunicação adequada do conteúdo matemático, identificar e resolver conflitos de significado e dificuldades de aprendizagem relacionadas com o modo de interação em aula, desenvolver competência para a avaliação formativa dos alunos. A idoneidade 
Educação Matemática Sem Fronteiras, Chapecó, v. 1, n.1, p. 23 - 39, jan-junho,2019. mediacional será alta quando o professor conhecer o papel dos recursos manipulativos e informáticos para a aprendizagem da Matemática, suas limitações e possibilidades e desenvolve competência para gestar o tempo de ensino (Godino et al, 2013).

Por meio desse guia, se o professor adquire competência em aplicá-lo pode ter facilitada sua tarefa de planejar, implementar e avaliar processos instrucionais idôneos, sejam esses processos uma sequência de ensino, um curso de formação inicial ou continuada de professores, um livro didático, uma tarefa específica ou respostas dos estudantes.

\section{Metodologia}

A presente pesquisa tem uma abordagem qualitativa, pois é a que melhor propicia a análise da realidade que se propõe a investigar. Segundo Sandín (2010, p. 127) "a pesquisa qualitativa é uma atividade sistemática orientada à compreensão em profundidade de fenômenos educativos e sociais, à transformação de práticas e cenários socioeducativos, à tomada de decisões e também ao descobrimento e desenvolvimento de um corpo organizado de conhecimentos".

Para tal análise foi desenvolvido um encontro de formação durante a Semana Acadêmica do Curso de Matemática - Licenciatura de uma Instituição de Ensino Superior (IES) pública do Estado do Rio Grande do Sul, Brasil. A proposta constituiu-se de uma oficina, de quatro horas, que visava mobilizar os conhecimentos didático-matemáticos sobre os números racionais dos participantes, futuros professores de Matemática.

Nesta oficina participaram 26 licenciandos e foi organizada em dois momentos. No primeiro momento tratou-se de como os participantes entendem/definem um número racional e como empregam esse conhecimento em uma situação-problema. Cada participante elaborou a sua resposta e, após, foi socializado com o grande grupo.

No segundo momento, os licenciandos se organizaram em trios e receberam duas situações-problema. Como haviam 8 trios e 1 dupla, 3 grupos receberam os mesmos problemas. O passo seguinte foi unir os grupos com os mesmos problemas para que esses novos grupos elaborassem uma solução, ou seja, que fossem rediscutidos os procedimentos e estratégias de solução. E, por fim, foi compartilhado, entre todos os alunos, as soluções e encaminhamentos elaborados e concomitantemente os formadores foram indicando e discutindo as possiblidades e definição do significado que o número 
Educação Matemática Sem Fronteiras, Chapecó, v. 1, n.1, p. 23 - 39, jan-junho,2019.

racional assumiu nas situações-problema.

A seguir são apresentados os resultados dessa oficina. Os dados foram levantados por meio dos registros das atividades supracitadas dos licenciandos.

\section{Resultados e discussões}

A formação de professores de Matemática, em específico, tem avançado nas últimas décadas e apontando os conhecimentos que os professores devem possuir para um processo de ensino idôneo. Por meio do modelo CDM, optou-se, neste estudo, a faceta epistêmica para análise dos dados pois engloba os conhecimentos comum, ampliado e especializado do professor no tópico específico de números racionais.

Os indicadores previstos para uma idoneidade epistêmica do processo de formação desenvolvido perpassa desde seu planejamento, que buscou instigar os conhecimentos didáticos e matemáticos dos licenciandos para que fossem produzidos conceitos, representações do mesmo objeto, estratégias de solução e encaminhamentos para superação de concepções errôneas.

Diante desses indicadores, são apresentados e discutida a mobilização de conhecimentos dos licenciandos no segundo momento da formação. Isto é, nos encaminhamentos, estratégias de solução e conhecimento matemático empregado ao desenvolver as cinco questões que potencializavam as trocas de registros do número racional, como também, os seus diferentes significados.

Inicialmente nesta formação, foi questionado por meio de uma lista de números, aqueles em que o licenciando exemplifica como um número racional com intuito de verificar se ele reconhece o campo numérico explorado. Na lista, havia números naturais, inteiros, dízimas periódicas, números irracionais e porcentagens. Dos 26 licenciandos, cerca de $23 \%$ responderam corretamente a questão. Na sistematização, com todos os alunos foi possível retomar a lista de números supracitada e identifcar os números racionais.

A primeira questão desenvolvida por 4 grupos, ilustrada na figura 2, emprega diferentes registros dos números racionais (porcentagem, frações e decimais), assim como, a comparação entre os números para determinar as posições na reta e o significado de medida, já que a reta poderia ser dividida em quintos ou de $20 \%$ em $20 \%$ por exemplo. 
Educação Matemática Sem Fronteiras, Chapecó, v. 1, n.1, p. 23 - 39, jan-junho,2019.

Figura 2 - Explorando o significado de medida do número racional

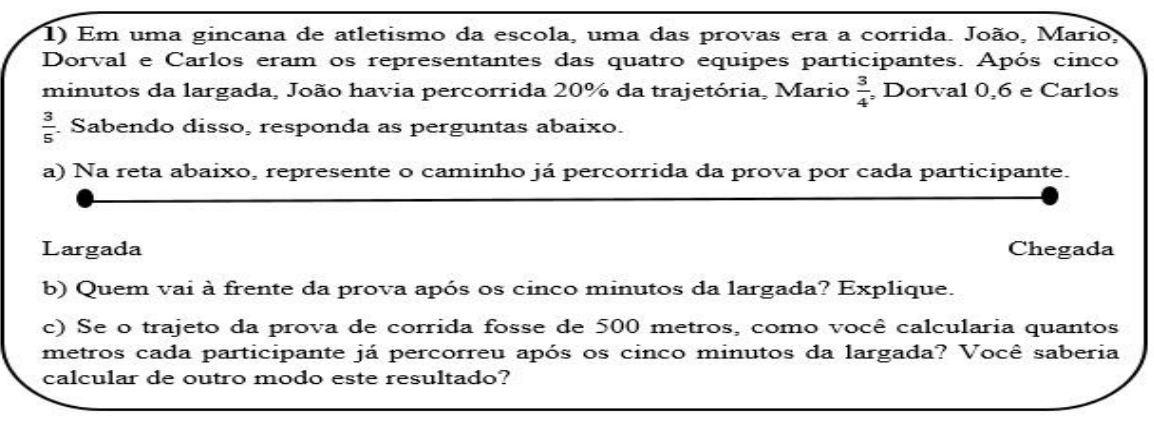

Fonte: da pesquisa.

Os licenciandos não apresentaram dúvidas/erros ao identificar a posição de cada um na reta (pista). Dois grupos adotaram o registro em decimal, um grupo em fração e um grupo em porcentagem. Percebeu-se que houve uma variação de registro, estimulada pela própria questão, e o grupo adotou o mais familiar para si.

$\mathrm{O}$ item (c) da questão, além do conhecimento matemático, esperava-se dos licenciandos a argumentação e/ou diferentes estratégias de solução. Dois grupos apenas responderam com o significado de operador do número racional, isto é, 500 vezes o número de metros que cada menino percorreu. Um grupo apresentou 3 procedimentos para obter a solução desejada, conforme ilustrado na figura 3. O primeiro procedimento empregando o significado de operador, o outro empregando a regra de três simples e o último procedimento, empregando o significado de medida.

Figura 3 - Registro de um grupo ao responder o item (c) da Questão 1.

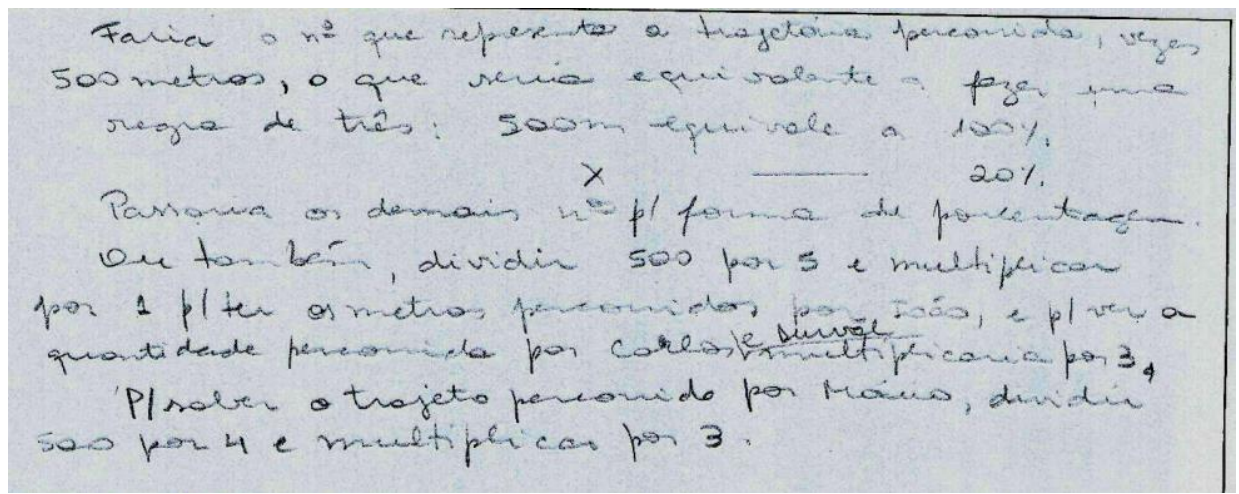

Fonte: da pesquisa.

A segunda questão, desenvolvida por 4 grupos, apresenta o significado de quociente de um número racional, assim como, estimula a compreensão do licenciando a uma resposta hipotética errada dado por um aluno. 
Educação Matemática Sem Fronteiras, Chapecó, v. 1, n.1, p. 23 - 39, jan-junho,2019.

Figura 4 - Questão que explora o significado de quociente de um número racional

$5)$ Certo dia durante a aula, a professora estava distribuindo folhas em branco aos alunos para realização de uma atividade. Nesta aula, estavam presentes quatro alunos e a professora tinha, no momento, 3 folhas.

a) cada aluno receberá uma folha?

b) cada aluno receberá pelo menos meia folha? Justifique?

c) qual quantidade de folha cada um receberá? Se recebermos como resposta $\frac{3}{4}$ ou $\frac{4}{3}$ do aluno, qual foi sua interpretação da situação proposta?

Fonte: da pesquisa.

Os itens (a) e (b) foram respondidos de forma correta pelos licenciandos, empregando, nas suas respostas, os registros de decimal, fração e na forma de desenho (representação das folhas cortadas). No item (c) ficou claro aos participantes que a resposta correta esperada seria $\frac{3}{4}$ da folha para cada aluno. Sobre a interpretação da resposta $\frac{4}{3}$ os alunos responderam que “ $\frac{4}{3}$ dividiria 4 pessoas para as 3 folhas”; "simplesmente faz a divisão simples, o maior pelo menor"; " $\frac{4}{3}=1$ folha $+\frac{1}{3}$ da folha". Ao apresentarem suas respostas ao grande grupo, os licenciandos perceberam o quanto o professor precisa compreender uma resposta (raciocínio) para poder auxiliar um aluno e promover a sua aprendizagem.

A terceira questão desenvolvida por 4 grupos, explora o significado de parte/todo e estimula diferentes procedimentos para obter a solução. A figura 5 ilustra a situação.

Figura 5 - Questão que explora o significado de parte/todo do número racional

2) Do salário João, ele gasta $\frac{2}{5}$ com o aluguel. Do que sobrou gasta a metade com alimentação. Da segunda sobra coloca $\frac{1}{3}$ na poupança. Restando $R$ \$ 300 . Qual o valor do seu salário? É possível determinar o salário de João por quais métodos (representações)?

Fonte: adaptado de Onuchic e Alevatto (2008).

Apenas um grupo conseguiu determinar o salário de João empregando a ideia de uma equação, $x-\frac{2}{5} x-\frac{1}{2} \frac{3}{5} x-\frac{1}{2} \frac{3}{5} \frac{1}{3} x=300$, onde $x=1500$ reais é o salário de João. O procedimento adotado é bem mais complexo e os grupos não empregaram o significado de parte/todo que incialmente era esperado pelos formadores, por ser um raciocínio mais 
Educação Matemática Sem Fronteiras, Chapecó, v. 1, n.1, p. 23 - 39, jan-junho,2019. simples. Um grupo buscou a solução por porcentagem, conforme os dados do problema, porém chegou ao resultado que $20 \%$ era 300 e o todo 1800 . Os outros grupos não apresentaram uma solução coerente. Quando a solução foi exposta ao grande grupo empregando a ideia de equação e outros possíveis procedimentos (parte/todo adotando a visualização pictórica) ou porcentagem, os licenciandos, novamente, rediscutiram o conhecimento do professor: sua preparação ao organizar os objetivos da aula, os exercícios, as dúvidas recorrentes e diferentes procedimentos para obter a solução.

A figura 6 a seguir, ilustra a quarta questão que emprega o significado de razão do número racional.

Figura 6 - Questão que explora o significado de razão do número racional

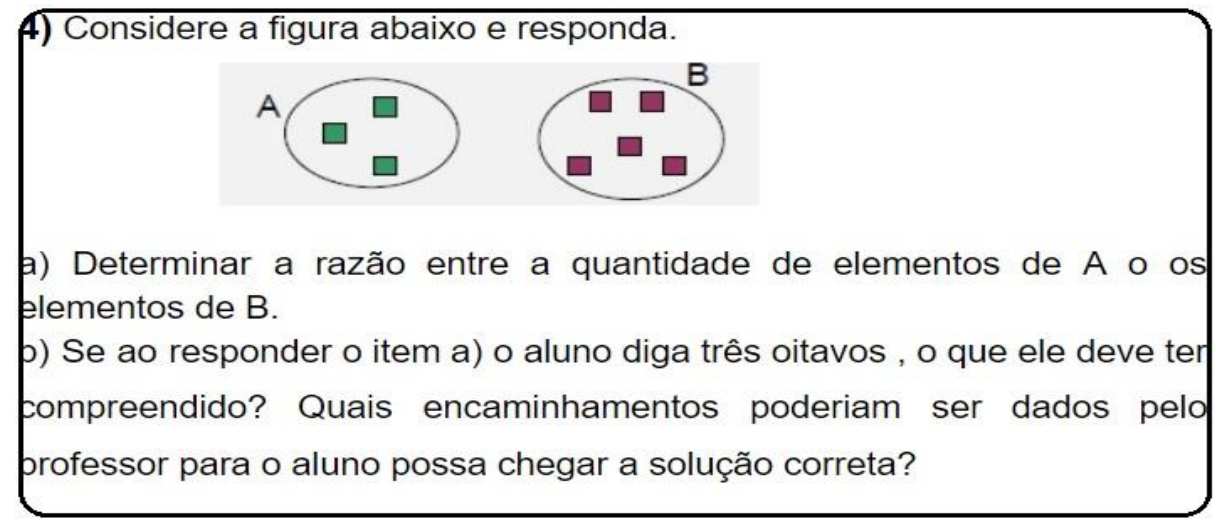

Fonte: da pesquisa.

Todos os grupos apresentaram como resposta ao item (a) a fração $\frac{3}{5}$. Durante as discussões nos grupos, foi indagado porque a fração $\frac{3}{8}$ estaria errada. Os alunos se convenceram que a fração $\frac{3}{8}$ estaria errada, pois o item (b) a encaminhava desta maneira. Percebeu-se, neste momento, a predisposição em considerar a fração como parte/todo e não como uma nova grandeza. Neste sentido, as produções de Silva (1997) e Magina e Campos (2008), identificaram que os professores costumam empregar situações de parte/todo como o principal contexto para o ensino das frações. Contudo, entende-se que o significado parte/todo é fundamental para o desenvolvimento de outros significados. Porém, quando o ensino fica restrito a este significado, a interpretação do número racional em outro contexto fica prejudicado. 
Educação Matemática Sem Fronteiras, Chapecó, v. 1, n.1, p. 23 - 39, jan-junho,2019.

As respostas ao item (b) permearam a ideia de não considerar as partes e, sim, o todo $(\mathrm{A}+\mathrm{B})$, como por exemplo "o aluno somou os elementos e em seguida dividiu pelo resultado da soma destes conjuntos, resultando em $\frac{3}{8}$." O único encaminhamento proposto para elucidar a solução foi "para o aluno chegar na solução correta, primeiramente o professor deveria mostrar que os conjuntos A e B são distintos, ou seja, a razão está entre os conjuntos".

Ressalta-se que, durante a formação, os licenciandos demonstravam preocupação em determinar a solução correta - realizar o cálculo. Quando se tratava de encaminhar a superação de uma dificuldade ou procedimentos distintos para determinar uma solução, não apresentavam tanto empenho (atenção).

Apenas quando o formador estimulou a percepção dos diferentes significados com o grande grupo, os licenciandos observaram os procedimentos distintos que estavam sendo utilizados. Sinalizaram que não tinham conhecimento sobre os significados do número racional.

A quinta questão ilustrada na figura 7 emprega o significado de operador do número racional e foi desenvolvida por 2 grupos.

Figura 7 - Questão que emprega o significado de operador do número racional

5. a) $\mathrm{Se} \frac{2}{3}$ de 12 é 8 , por quanto tenho que multiplicar o 8 para obter 12 ?

5. b) Se minha receita de bolo pede 3 copos de leite mas eu só tenho 2, quanto devo tomar dos outros ingredientes para fazer o bolo usando esses 2 copos de leite?

5. c) Dado um retângulo com medidas 4 e 6 centímetros, obter um novo retângulo que tenha as medidas dos lados iguais a $\frac{3}{4}$ das medidas originais.

Fonte: da pesquisa.

O item (5a) foi respondido corretamente pelos os grupos, porém com registro decimal (multiplicar por 1,5 ) e o outro de fração (multiplicar por $\frac{3}{2}$ ). No item (b), um grupo respondeu $\frac{2}{3}$ e a forma pictórica dessa fração. O outro grupo realizou regra de três (adotando 3 como $100 \%$ e 2 equivalente a $x$, obtendo $x=66,66 \ldots)$. O item (c) foi 
Educação Matemática Sem Fronteiras, Chapecó, v. 1, n.1, p. 23 - 39, jan-junho,2019. respondido por um grupo e empregou o significado de operador para obter a solução $\left(\frac{3}{4}\right.$ vezes o valor do lado).

Na sistematização dos resultados os alunos expressaram seu entusiasmo pois , por meio das atividades, puderam construir conhecimentos relativos às diferentes representações e os diferentes significados de um número racional.

\section{Considerações finais}

O presente trabalho intentou identificar e analisar os conhecimentos mobilizados por licenciandos em Matemática durante uma formação, a partir do tema números racionais, sob a perspectiva do Conhecimento Didático-Matemático.

Os licenciandos dessa formação, que variavam de ingressantes a concluintes, apresentaram um distanciamento quanto ao ensinar. Por exemplo, não tinham uma grande preocupação em como encaminhar um questionamento para elucidar uma questão ao aluno do Ensino Fundamental com uma concepção errônea/dúvida.

Quando as discussões aconteciam no grande grupo e com a participação mais ativa dos formadores explorando diferentes procedimentos/registros de soluções, os alunos perceberam que a atividade proposta consistia muito mais do que saber fazer (conhecimento comum), mas, sim, de como explicar/ensinar (conhecimento especializado).

Embora as dificuldades de aprendizagem tenham surgido durante a formação, pode-se concluir que foi um momento rico e oportuno para troca de ideias, pensamentos e argumentos, como também, para refletir sobre os reais conhecimentos do professor ao ensinar números racionais no Ensino Fundamental, visando alcançar uma aprendizagem efetiva dos alunos.

\section{Referências bibliográficas}

BALL, D. L.; THAMES, M. H.; PHELPS, G. Content knowledge for teaching. What makes it special? Journal of Teacher Education, v. 59, n. 5, p. 389-407, 2008.

DUVAL, R. Registros de representação semiótica e funcionamento cognitivo da compreensão em matemática. In: MACHADO, S.D.A. (org). Aprendizagem em matemática: registros de representação semiótica. São Paulo: Papirus, p. 11-33, 2003. 
Educação Matemática Sem Fronteiras, Chapecó, v. 1, n.1, p. 23 - 39, jan-junho,2019.

GODINO, J. BATANERO, C. FONT, V. The onto-semiotic approach to research in mathematics education. ZDM. The International Journal on Mathematics

Education, v. 39, n. 1-2, p. 127-135, 2007.

GODINO, J. D., BATANERO, C. ; FONT, V. (2007). The onto-semiotic approach to research in mathematics education. ZDM. The International Journal on Mathematics Education, Vol. 39 (1-2), 127-135.

GODINO, J. D. Categorías de análisis de los conocimientos del profesor de matemáticas. Revista Iberoamericana de Educación Matemática, v. 20, p. 13-31, 2009.

GODINO, J.D. et al. Componentes e indicadores de idoneidade de programas de formação de professores em educação matemática. REVEMAT: Florianópolis, v. 08, n. 1, p. 46-74, 2013.

KIEREN, T. On the mathematical, cognitive, and instructional foundations of rational numbers. In Lesh, R. ( Ed.) Number and measurement: Paper from a research workshop. Columbus, Ohio: ERIC/MEAC, 1975, p.101-144.

KIEREN, T. Personal Knowledge of rational numbers: its intutive and formal development .In: Hiebert, J and Behr, M. ( eds.) Number Concepts and Operations in the Middle Grades. Hillsdale, New Jersey: Erlbaum, 1980, p. 162-180.

LAMON, S. J. Teaching fractions and ratios for understanding: essential content knowledge and instructional strategies for teachers 2 ed. Mahwah: Lawrence Erlbaum Association. 2006.

MAGINA, S.; CAMPOS, T. A fração na perspectiva do professor e do aluno dos dois primeiros ciclos do Ensino Fundamental. Boletim de Educação Matemática: Rio Claro, ano 21 , n. 31,2008 , p. $23-40$.

ONUCHIC; L.R.; ALEVATTO, N.S.G. As Diferentes "Personalidades' do Número Racional Trabalhadas através da Resolução de Problemas. Boletim da Educação Matemática: Rio Claro, ano 21, n. 31, p. 79 -102, 2008.

PINO-FAN, L.R.; GODINO, J. Perspectiva ampliada del conocimiento didácticomatemático del professor. Paradigma, v. XXXVI, nº 1, 2015, p. 87-109.

PINO-FAN, L.R.; FONT, V.M.; GODINO, J. El conocimiento didático-matemático de los professores: pautas y critérios para su evaluacion y desarrollo. 2014. Disponível em: $<$ http://docente.ulagos.cl/luispino/wp-content/uploads/2014/09/Pino-Fan-et-al.2014_Extracto-sin-portada.pdf> Acesso 11 set 2018.

RIPOLL, B.R.; RIPOLL, C.C.; SILVEIRA, J.F.P. Números racionais, reais e complexos. Porto Alegre: URFRGS Editora. 2ed. 2011. 
Educação Matemática Sem Fronteiras, Chapecó, v. 1, n.1, p. 23 - 39, jan-junho,2019.

ROMANATTO, M.C. Número racional: relações necessárias a sua compreensão. 1997. 169f. Tese (Doutorado em Educação) - Faculdade de Educação, Universidade Estadual de Campinas, Campinas, 1997.

SANDÍN ESTEBAN, M. P. Pesquisa qualitativa em educação: fundamentos e tradições. Tradução de Miguel Cabrera. Porto Alegre: AMGH, 2010.

SCHOENFELD. A.; KILPATRICK, J. Towards a theory of profiency in teaching mathematics. In TIROSH, D.; WOOD, T.L. (Eds.) Tools and processes in mathematics teacher education Rotterdam: Sense Publishers. p. 321-354, 2008.

SILVA, M.J.F. Sobre a introdução do conceito de número fracionário. 1997. 245f. Dissertação (Mestrado em Ensino da Matemática), Pontifícia Universidade Católica de São Paulo, São Paulo, 1997.

SHULMAN, L. S. Those who understand: Knowledge growth in teaching. Educational Researcher, v.15, n.2, p. 4-14. 1986.

SHULMAN, L. S. Knowledge and teaching: Foundations of the new reform. Harvard Educational Review, v. 57, n.1, p. 1-22, 1987. 